\title{
Punished For Being Normal! A Culturally Relevant Critique of the Deviant Behaviors of Minority Millennials
}

\author{
Miriam Chitiga \\ Educational Leadership and Policies \\ Fayetteville State University \\ Fayetteville, North Carolina
}

\begin{abstract}
Socially disadvantaged minority students, including African American students are disproportionately, singled out for disciplinary action and behavior intervention programs in schools in the United States. The article draws from triangulated evidence sources, including the researcher's experience as an educational leadership administrator, faculty member teaching educational leadership, research, and policies, classroom lesson observations, collaborations and input from practicing teachers and principals, and literature reviews. Perhaps one of the readily accepted collective stereotypes is that socially disadvantaged minority students including AfricanAmerican children are more prone to engage in negatively deviant behavior than any other group of students. This factor is one of the major contributors to the disproportionately high number of discipline referrals, parentconferences, in school and out of school suspensions, grade retention, underperformance, alternative school placements, school-to-prison pipeline, and dropout rates, among the seemingly endless list of other problems minority students face. To help educational leaders and teachers to better understand more of the diverse students that they serve, the paper critically examines some of the commonly misinterpreted behaviors of black K-12 students and offers possible culturally relevant interpretations and rationale for such otherwise 'normal' behavior. Further, for each of the behaviors analyzed, the paper suggests alternative avenues for re-examining culturally 'normal' behavior that mainstream public schools routinely label as deviant. The article argues that leaders and other educators ought to continue to critically examine this issue, in order to deepen their insights into the cultural and home backgrounds of their students, and to find novel mechanisms of labelling, curbing, and appropriately dealing with otherwise normal behavior that is mischaracterized as deviant. The paper also suggests innovative ways for educators to help students and families identify potential triggers and causes for behavior and attitudes that are likely to be construed by mainstream educators as negative deviance.
\end{abstract}

Keywords: Punished Deviant Behavior; Disproportionate Discipline; Minority Students; Linguistic Differences; School-to-prison pipeline. 


\section{Background}

The problems that minority students face within the education systems, can be best understood is examined within the larger societal context of the challenges that minority populations - who are often marginalized - are compelled to endure in their engagement within predominantly monolithic mainstream cultures. Majority perceptions of the behaviors that are considered acceptable or deviant determine the benchmarks for measuring the conduct of the minority groups, in various social situations. This is especially problematic in the publicschool sector, where the behaviors and tendencies that fall outside the confines of established norms and perceptions are either formally classified or ultimately labeled deviant. Students from minority groups struggle with establishing a healthy personal concept, because they are constantly under scrutiny from teachers, who expect them to act within the confines of a behavior and value system that is derived from the majority culture - a value system which is alien to them and which seeks to squeeze them in a constrictive mold of mainstream culture. The dilemma that these students face is that the more they try to act in resonance with the conventional and fixed standard of the dominant group, the more they lose a sense of self and feel alienated. Conversely, by resisting the majority culture in an effort to preserve theirs, they expose themselves to disproportionate prejudices and disciplinary consequences.

Research shows that minorities, including African American students, are often disproportionately targeted by the United States criminal justice system (Brewer \& Heitzeg, 2008; US Bureau of Justice Statistics, 2007; Cole, 1999). For example, Herrera, Holmes, \& Kavimandan (2012) discuss the problems that African American students face as they try to navigate the mainstream Eurocentric education system. Such ideological baggage, which is premised on a monolithic culture, stifles the potential of many African American learners and adversely clouds the perception of mainstream teachers towards the behavior, attitudes, and potential of minority students. Every semblance of expression of minority students is a field of contestation in which the worst pathetic constructions are formulated that continue to feed in the mantra of the pathetic performance of the minority students especially the African American students. To these teachers, the time-honored adage 'it's all yellow to the jaundiced eye' grows in relevance because the teachers, as expected, now 'see' hopelessness and deviance only. Indeed, one of the most widespread, deeply entrenched, and readily accepted social stereotypes is that socially disadvantaged minority students are more prone to engage in a deviant behavior than any other group of students (Becker, 1963; Jabbra, 2001; Moore, 2003). Critical theorists and critical race theorists view power hierarchies in terms of oppressive groups that impose their views, cultures, and languages on the oppressed (Freire, 2010; Robinson \& Lewis, 2017; Weber, 2010). The wide adoption of zero-tolerance discipline policies and harsh, and punitive suspension policies further complicates the relationship between the schools and students of color and other minorities, including those with learning and other disabilities. The then Assistant Attorney General Thomas E. Perez states, "Education should offer a lifeline to those students for whom a successful future is not predetermined ... education should be the key that opens the door to a better future," ( 
https://www.justice.gov/archives/opa/ blog/civil-rights-and-schooldiscipline).

\section{Introduction}

This paper does not focus on the types of punishment that schools use to discourage and deal with the culturally misinterpreted behaviors of AfricanAmericans; instead, it aims to elucidate both the behaviors and the mainstream interpretations, in an effort to help educational leaders and educators rethink and interrogate their own behaviors, reactions, and understanding of the diverse students that they serve. In this way, this paper contributes to a growing body of literature that critically examines the institutionalization of policies and behaviors that disproportionally disadvantage minority students in ways that hinder or demolish their chances of using education to open the doors to better futures, prosperity, upward social mobility, and as a tool to interrupt or end intergenerational cycles of poverty failure. Essentially, the problem emanates from the dissonance and disparities that exist between the different value systems and perceptions that guide the behaviors of the mainstream teachers and the minority students. These different perspectives, standpoints, and ideological underpinnings critically influence behaviors and attitudes of both parties. Owing to the mainstream teachers' general lack of understanding and or empathy for the totality of experiences and modes of expression of the minority students, any behavior by the student which runs contrary to the fixed script is perceived as deviance, and probably warranting disciplinary consequences. This further heightens the advocacy of a Cultural Responsive Pedagogy and Biography-driven instruction models of engagement between teachers and their students, especially those coming from a minority group. These pedagogies call for teacher educators to empower candidates those skills needed to create inclusive classroom environments, where diversity is valued. This could enhance culturally responsive pedagogy and biography-driven instruction, which emphasizes the need for teachers holistically engage students, taking into consideration their collective cultural backgrounds and experiences as crucial to their current values, psyche and behaviors (Herrera, et al 2012; Samuels, Samuels \& Cook, 2017).

Socially-disadvantaged minority students, often African-American and Latino, are disproportionately singled out for disciplinary action and behavior intervention programs in schools in the United States (Baker, Cameron, RimmKaufman, \& Grissmer, 2012). This is one of the major contributing factors to the alarmingly high number of discipline referrals, parent-conferences, in-school and out-of-school suspensions, grade retention, alternative school placements, under-performance, and dropout rates (Jenkins, 1995; Skiba, Michael, Nardo, \& Peterson, 2000). These visible trends in education have come to the attention of the public in recent years (Rocque, 2010). Educators should continue to critically examine this issue to deepen their insights into the behavioral challenges those students face, thereby finding better ways of curbing deviance, appropriately dealing with deviant behavior, and helping students and families identify potential causes of negative behaviors. Although, as noted above, both AfricanAmerican and Latino students are targeted in similar ways when it comes to discipline, this article concentrates primarily on African-American school age 
children and teens. In 2007, the National Urban League reported that only 43 percent of African-American males, compared to 78 percent of white males, graduated from high schools in the early 2000s (as cited in Baker, Cameron, Rimm-Kaufman, \& Grissmer, 2012). Moreover, according to the report presented by the Council for Exceptional Children \& National Alliance of Black School Educators (2002), African-American children are more likely to be referred to receive special education on the basis of mental retardation, emotional disturbance, or the presence of a learning disability. Although African-American students between the ages of six and twenty-one make up less than 15 percent of American society, they are represented by 20 percent of special education students (Council for Exceptional Children \& National Alliance of Black School Educators, 2002). These discrepancies are quite disturbing, especially with regard to the quest to offer all students the opportunity for upward social mobility. Such disproportionate group membership can be traced to many other areas of the education and criminal justice systems in the United States (McKenna, 2013; Skiba, Poloni-Staudinger, Gallini, Simmons, Feggins-Azziz, 2006; Zhang, Katsiyannis, Ju, \& Roberts, 2014).

While the debate exists on the foundation of the problem mentioned above (whether African-Americans are more likely to commit disciplinary violations or whether they are more likely to be punished harshly for similar actions), Tyler and colleagues (2008) explained academic difficulties for minority students by referring to lack of connection between home and school environments for these students. Schools are often tasked with assuming responsibility for teaching appropriate behaviors to children and teens (Jenkins, 1995). When home lives are significantly different and, in some cases, even contradictory to the desired school environment, the student is caught in between.

Delinquency is defined as "acts against persons or property that disrupt the educational processes of teaching and learning" (Jenkins, 1995). Delinquency and deviance, like many other social aspects, are instrumental in nature. They also can be perceived as tools of social control and maintenance of the status quo (Ulmer, 2000). These definitions allow for social stratification (Phelan \& Rudman, 2010). Deviance is determined by the powerful forces of society with the intent of disadvantaging and labeling certain others, who are often also members of the oppressed, marginalized, disenfranchised groups (Ulmer, 2000). In other words, the dominant group defines deviance. In 2008, Higgins and Mackinem declared: "When we think about deviance, we should not just have in mind some "fringe" segment of society. When we think about deviance, we can think about ourselves, too." Certain behaviors of school-age children are labeled as normal, while other behaviors are deemed deviant. Often, in attempts to quickly address delinquency and deviance at schools, finding answers of why students behave a certain way are overlooked. This paper addresses commonlyconsidered "deviances" and offers alternative views when it comes to attending to them in a classroom environment.

\section{Rationale}

Home culture and socialization often influence the nature of inter- and intracultural interactions. While some behaviors are accepted as normal at home, 
those very same behaviors might be viewed as acts of delinquency at schools. Those students, who do not adhere to traditional approaches in education, are labeled as "disabled" (Guild, 2011; McKenna, 2013). Some experts believe that certain learning patterns, including oral, physical, and peer engagement, are essential for African-American children and teens (Guild, 2011; Watkins, 2002). In order to improve the educational experiences of African-American children and to make progress in correcting historic and current injustices, it's necessary to identify areas of concern-where mere cultural differences may be misidentified as delinquency - and to suggest solutions to them. These areas of concern are loud voices and back-talk, language and linguistic differences, and rhythmic and kinesthetic learning. Furthermore, because of societal stratification systems that serve to sort people into categories that correspond to the way that valued resources are distributed and rationed, minorities are often disadvantaged by certain laws and regulations that often become overly punitive to certain segments of the population. These minorities often include, but are not limited to the following groups: the less politically and economically powerful, the poor, those with mental/physical/emotional disabilities, women, foreigners, people of color and others whose features depart considerably from the mainstream and the policy makers, One set of policies that has disproportionally jeopardized African American students is commonly referred to as the "zero-tolerance discipline policies, [which] impose increasingly harsher punishments for seemingly minor infractions," (US Department of Justice, 2010, https://www.justice.gov/archives/opa/blog/civil-rights-and-school-discipline. The negative consequences of zero-tolerance discipline policies have a disproportional effect on students of color, leading to the increase of the criminalization of Black, Latino, and disabled students. Therefore, to compound the socio-cultural misinterpretations of student behavior in schools, the legal and policy components further discriminate against minority students, including African-American children. This legal complication is a major factor in fueling the school-to-prison pipeline that is evident in the fact that blacks are disproportionally represented in US prisons.

\section{Loud Voices and Back-Talk}

One of the major complaints teachers have about African-American students is that they are too "loud" or "noisy" (Fordham, 1993; Morris, 2007). This, in the educators' eyes, deserves disciplinary action, albeit not as severe as that given for other "disruptive behaviors." Anyone who has spent time with black youths has heard them talk on the phone, to each other, joke around with each other, and simply engage in various conversations. The majority of time, they are generally boisterous and their voices are strong and quite audible (Morris, 2007). A good number of them speak loudly in happy conversations and their voices and conversations can be heard clearly in the next room. Generally, they are not trying to hide anything or gossip about anybody-they simply speak freely (Fordham, 1993). Their "loudness" is often mistaken for aggression or intentionally disruptive behavior.

The "loudness problem" like many of the cultural behaviors that Black students are punished for, is also problematic for some adults in the United States. Most students speak at the same volume that they hear adults and their 
peers speak in the same in a variety of settings. For example, eleven Black female book club members were unceremoniously kicked off a Napa Valley tour train, for being too loud for other passengers. (Napa Valley wine train incident. http:/ / beta.latimes.com/local/lanow/la-me-ln-wine-tour-settlement-20160419story.html). "Loud" voices are used at home: in conversations with parents and siblings, with peers, at church by the pastor and congregation as they praise and worship together, and in the community. African-Americans are often perceived as loud talkers and loud laughers. Those unfamiliar with this phenomenon may look at African-Americans engaging in "loud" talks, referred to as talking with an attitude (TWA) by some scholars, negatively (Koonce, 2012; Troutman, 2010). However, to the members of this group, TWA can also be perceived as positive and even required (Koonce, 2012). Simone (2013) reported that this stereotype of "loudness" is especially harsh on African-American females.

However, the need to speak up to be heard is culturally ingrained from childhood-in African-American churches, at assemblies, at home, and even sometimes in school. There is nothing out of the ordinary in "loud" interactions in the home communities of these students. In various instances, young conversationalists speak in their same, "normal" voices in their home environments. If anything, they might be encouraged to speak louder as might be the case in a church or in an assembly, when the pastor or the speaker might call to them to respond to a greeting or question. In almost every educational assembly or other event the author of this article attended, the speaker, after the first greeting, would beckon the students to shout or respond louder, often using remarks such as: "Surely, you can do better than that! "I can't hear you!" Let's try again!" In class, it is common for teachers to ask those students who respond to the teacher's prompt in low voices with a comment: "Speak up, so that everyone can hear you!" Therefore, even in formal and semi-formal educational settings, these young students "speak up," so that they can be acknowledged. Thus, when these same students are punished for doing something that they have been socialized, trained, and encouraged to do in a variety of settings, including the formal classroom, they are taken aback. Teachers tend to plead for the use of an "inside voice." And what do you do when your inside voice sounds obnoxious to others?

Especially for younger students, this dissonance can be very confusing and disturbing, as they struggle to understand what the rules are, and how and why they are variedly applied. Such confusion can lead to more disorientation for the students, as they try, in vain, to make sense of the new, unclear, unexplained rules of the alien school culture. For some of their parents, too, this seemingly inconsistent application of the rules can be very frustrating and difficult to comprehend, let alone explain to their children. In situations where this and similar problems persist, it would be unrealistic for teachers and other school officials to expect parents to be their allies in helping encourage students to enthusiastically attend school and diligently pursue education. If both parents and students are confused, frustrated, and suspicious of the school culture, they may become stronger allies against the school culture and what it stands for. In addition to speaking loudly, African-American teens are sometimes also reprimanded for talking back to an educator. Sometimes backtalking is viewed by educators as a sign of disrespect. However, United States 
culture encourages individuality and self-expression. In 1996, Baumrind stated that issues of "personal agency and autonomy" were not only to be expected during preschool years and adolescence, but were absolutely necessary during these periods of finding one's voice and identity. We learn about freedom of selfexpression and the notion that all men are created equal, yet we are taken aback when a student speaks up or has an opinion significantly different from ours.

We present the students with conflicting ideas. On the one hand, they are encouraged to express themselves freely, and on the other hand, diligently trained not to talk back. No doubt, this is confusing for a developing mind. Flanagan (2013) presented his view on a child who talked back; it was divided between being a parent and a psychologist. Which side does an educator pick? According to Flanagan (2013), students should be allowed to tell their own story and voice their own opinion. Otherwise, would prevent us from viewing ourselves as useful to the community and the world in general and would allow the world to use us instead. Outlined below are some possible solutions.

\section{Possible Solutions}

Given that the teachers and school officials are often the only people, in this "circle" (of students, teachers, parents, guardians, community, etc.), who are aware of the variations of the rule application and the rationale for such, the onus is on them to painstakingly explain to both the students and their guardians the differences in implications and expectations for voice-loudness in the school setting. For example, students can be trained to recognize appropriate instances to use the "inside" voice (which should be clarified by the educators) as opposed to the "outside" voice. As many culturally aware teachers often do, it is essential to socialize the students into the "new" culture by helping them understand how and when to appropriately "code-switch" between their home culture and their school culture (Flowers, 2000). Higgins and Mackinem (2008) noted that while we may "abhor the destruction caused by some deviance," we must realize that "deviance is fundamental to human life." Thus, an acknowledgment must be made that what is often labeled as destructive loudness and back-talk might be the emergence of "self-assertive aspects of human nature" (Baumrind, 1996). Educators also need to realize that this selfassertiveness often creates the foundation for self-esteem and competence (Baumrind, 1996). This very self-assertiveness is necessary for the educational process and dialog.

\section{Language and Linguistic Differences}

Many public schools prohibit-de facto - the use of any other language other than English-specifically the Standard English dialect used as the official medium of instruction and all other communication in schools. Where the "prohibition" rules do not specifically mention language use, the latter is implied and punishable through various other subtle, but consequential ways. Intentionally or unintentionally, the practice discriminates against many traditionally American citizens who can claim no other language but English just not the officially sanctioned language of the school, i.e., Standard English. For example, those who do not use Standard English for academic writing and presentations usually get penalized, grade-wise, for their "sub-standard" 
linguistic skills. This group includes, but is not limited to, white Southern Americans whose home languages comprise a variety of Southern White English dialects, and African-Americans, who speak what is collectively referred to as African-American Vernacular English (AAVE) and also is referred to as the Black Vernacular English (BVE) (Mayher, 1974). Research shows that the majority of African-American students switch between "a variety of social registers to produce inherent variability in the features of their speech" (Linn, 1975).

Given the pivotal role that language and culture play in socialization and identity, students who are prohibited, punished, and/or disadvantaged for using their home languages during class time and certain school activities often feel alienated from school. Consequently, many find it difficult to overcome the socio-linguistic barriers quickly enough to master the subject content to the degree required for educational success. Some would say that it is not the young students who have a cultural deficit. Instead, it is the adult, school officials who do, as most lack the knowledge and or appreciation of the cultural diversity of their students. Those who have some knowledge of different cultures, even those who might share the same cultural roots with the students in question, might nevertheless lack a full appreciation of how to incorporate home culture into the middle-class school culture.

\section{Possible Solutions}

Teachers should make an extra effort to recognize the variants of Standard English often utilized by African-American students (Linn, 1975). Moreover, avoiding a stereotypic view of speech differences can teach a student that the use of Standard English does not necessarily entail the rejection of the students' culture and favoritism of the white middle-class culture (Linn, 1975). In 1974, Mayher recognized that Black Vernacular English should be regarded as a recognized dialect of English. This dialect is fully capable in "principle of expressing anything which can be meant in any dialect in English." Most English teachers receive their education on the foundation of the traditional language model (the use of the Standard English), so they are unfamiliar with the model of BEV. If a student is given an opportunity to use the language he or she is accustomed to, it is easier to establish clear standards and expectations for all students for written and spoken languages.

It is essential to help all students feel and believe that their home cultures are key to their learning and personal growth. In a study of the implementation of an education language act in another multilingual nation it was found that, there was dissonance among their attitudes on the most appropriate medium of instruction held by students, teachers, principals, and parents (Kadodo \& Zanga 2015). Lindsay (2003) stated that only the "integrative meshing" of cultures and subcultures of educational settings can produce fruitful results. Educators should help students understand the value of learning new cultures without erasing their home cultures. Students benefit from understanding the benefits of being multicultural, with the ability to code-switch both language and behaviors in different contexts, as appropriate. They should be helped to appreciate the fact that it is okay to speak fluently, both Standard English and their home dialect in the appropriate linguistic contexts. This cannot be achieved by 
punishing them for using their home language in class; instead, teachers should take the opportunities to illustrate how different dialects or languages are best suited for different linguistic environments, as well as illustrate areas of overlap. Further, educators should feel free to code-switch between dialects for pedagogical enhancement. For example, teachers could code-switch for emphasizing certain disciplinary issues if they feel the specific students would respond best to.

\section{Rhythmic and Kinesthetic Learning}

Another common problem that teachers complain about is that black students often sing at inappropriate times. Some of them suddenly break into song in the middle of the lesson. Others sing during "quiet" times when they are supposed to be working silently on individual assignments. Teachers and some students might complain about the "disturbing" noises or "disruptive behavior."

It is widely acknowledged that internal rhythms helped many African ancestors survive the horrors and hardships of enslavement in the forced diaspora and colonization on the continent of Africa (Breckenridge, 2000). Accordingly, a rich musical tradition has developed that provides emotional soothing and spiritual enrichment, helps people cope with external pressures, helps them ease the strain of inhumane physical labor, strengthens social cohesion, provides voice to the voiceless, and provides a vehicle for transmitting in-group coded messages. Music has served as an integral part of health maintenance as well as emotional and social stability (Breckenridge, 2000). Music continues to be an extension of the African-American culture and is regarded as a necessity for one's daily functioning in this culture (Carter, Hawkins, \& Natesan, 2008). Therefore, when young African-American students sing to themselves while doing homework, they are merely doing so to reduce the intensity of the mental stress that can be brought about by academic tasks. They generally have no intentions of being disrespectful to their teachers and peers or disruptive to the class. Teachers usually give students the rules and the accompanying penalties for breaking them; in some cases, they might also provide external incentives and rewards for following the rules. However, simply giving them the rules, without explaining the differences in home and school cultures and explaining the intrinsic advantages of following those rules might not help the students feel motivated enough to embrace the "new" cultural norms.

To further explain the rhythmic nature of African-American students, Carter, Hawkins, and Natesan (2008) relied on the term verve. Boykin (1983) described it as the tendency for "energetic, intense, stylistic body language and expression." This propensity for stimulating learning environments is often relevant for African-American children, and is said to have its roots in West Africa, where a large number of African-Americans originated. If children are not given the proper opportunities to move about as well as express themselves through such movement, they find those opportunities without any intention to cause mayhem. Carter, Hawkins, and Natesan (2008) referenced several authors who believe that African-American children are often punished for their natural propensities, because they must adhere to the standards designed by and for European American, middle-class, schooling. This culture creates a conflict for 
young children and teens that are used to home cultures that promote free expression.

Boykin (2001) stated that students with highly vervistic expressions are regularly referred to as having poor concentration and organizational skills. Verve can be expressed in many ways. For instance, these students might thrive in rather noisy working environment and prefer working collaboratively rather than individually. They also might show preference to interactive learning rather than passive, individual tasks such as quiet reading and note-taking.

\section{Possible Solutions}

Boykin (2001) proposed several instructional techniques that can be effective in addressing the vervistic nature of many African-American children. These techniques include communications and interactions that encourage selfexpression. The use of rhythmic language, expressive gestures, and opportunities for collaboration, movement, and lively discussions are more likely to encourage productivity in students. Students should be given ample chances to merge home environment. Diversity should be celebrated not punished in the classrooms throughout the United States.

\section{Putting It All Together}

In the late 1970s, first attempts were made to institutionalize reforms that can make educational settings as well as the teacher education curricula more ethnically and culturally inclusive (Banks, 1979). A major goal of such reform was to reduce racial and ethnic prejudice and discrimination. Although, since the 1970s, much has been achieved through social reformation, more work needs to be done. We cannot completely disregard the history and must recognize that the societal rules were created by the ruling class (Ulmer, 2000). Some scholars refer to this as "Anglo-conformity" (Banks, 1979). It is imperative to recognize that the disciplinary climates of every school emerge out of a "complex interaction" between the demographic characteristics of everyone involved, as well as interpersonal communities surrounding the school environments (Arum, 2000). Discontinuity continues to exist between a child's home experience and the value structures typically encouraged in many public schools (Council for Exceptional Children \& National Alliance of Black School Educators, 2002). Demanding complete separation of home and school cultures from students in not only unnecessary, but also impossible. Cross-cultural competence of educators is very important for all students (Banks, 1979). This competence and respect of diversity discourages over-representations on African-American students when it comes to school suspensions and other infractions. It also stops the alienation of any students from the rest of the school.

If, as educators, we believe as John Dewey did, that formal education is not preparation for, but life itself, then we must ask ourselves what kind of life our schools are giving our students. Even if we believe that education is simply the preparation of the young for their future roles, we still need to ask ourselves what kind of life we are preparing these young and vulnerable students of life for. Are we giving them or preparing them for a life where their cultures and personal identities are inferior and rejected, and even punished? Freire and other transformative educators believe that teachers owe it to the students and to their 
societies to help students acquire the skills and knowledge types needed for the critical examination and consequent transformation of their societies into freedom filled, socially just ones. If schools are microcosms of their societies, perhaps it is time for communities to come together to transform those societies that are mirrored by those failing schools whose cultures alienate many of our students, especially the economically, culturally, physically, and mentally different, and racial, ethnic, gender, and religious, minorities. If educators, policy makers, and citizens at large make a concerted effort to strive for and implement social justice across the social landscape, we will begin to see schools that value and celebrate all students, regardless of their backgrounds.

More progress will be made only when more and more educators, especially educational leaders, acknowledge the fact that some discrimination continues to exist and when the rest of the country engages in reformation. U.S. Department of Education (2014) noted that, although many teachers are familiar with making difficult decisions in practicing discipline, these decisions often come with unfair and unnecessary use of suspensions and expulsions. Many educators continue to rely on outdated laws that were created at the turn of nineteenth century to keep students at schools instead of being made to work in the fields and factories (PBS, 2014). Today, students might receive a misdemeanor charge for missing a certain number of unexcused absences. Is the punishment going too far? Is it going even further for the minority students? Often, authorities practice criminalization of behaviors without making any attempt of understanding it. It takes time and resources to develop alternative ways to discipline a classroom, while celebrating diversity. It is the job for the whole county to make sure that every student has an equal opportunity to succeed at school and life in general. Resistance to change in ideology might be the root of our problem. Thus, it is vital to increase the occurrences of meaningful, honest, and deliberative dialogue among educators, students, counselors, families, community and other influential leaders, policy makers and implementers, and government agencies, including those in the justice and education departments.

\section{References}

Addressing over-representation of African American students in special education: The prereferral intervention process. An administrator's guide. (2002). Council for Exceptional Children, \& National Alliance of Black School Educators. Retrieved from http://www.dcsig.org/files/AddressingOverrepresentationAfricanAmerican guide.pdf

Are some U. S. school discipline policies too punitive? (2014). PBS [video]. Retrieved from http://video.pbs.org/video/2365151843/

Arum, R. (2000). Schools and communities: Ecological and institutional dimensions. Annual Review of Sociology, 26(1), 395.

Baker, C., Cameron, C., Rimm-Kaufman, S., \& Grissmer, D. (2012). Family and demographic readiness Predictors of school readiness among AfricanAmerican boys in kindergarten. Early Education and Development. 23. 823-854.

Banks, J. (1979). Shaping the future of multicultural education. The Journal of Negro Education, 48 (3), 237-252.

Baumrind, D. (1996). The discipline controversy revisited. Family Relations, 45(4), 405414.

Becker, H. (1963). Outsiders: Studies in the sociology of deviance. New York: The Free Press. 
Boykin, A. W. (1983). The academic performance of Afro-American children. In J. Spence (Ed.), Achievement and achievement motives. San Francisco: Freeman.

Boykin, A. W. (2001). Culture matters in psychosocial experience and schooling of African American students. Submitted for publication in the Harvard Education Review.

Breckenridge, S. L. (2000). Grooving body movements through bass lines: A tradition in African American music. Western Journal of Black Studies, 24(3), 175.

Brewer, R. \& Heitzeg, N. (2008). The racialization of crime and punishment: Criminal justice, color-blind racism and the political economy of the prison industrial complex. American Behavioral Scientist, 51(5), 65.

Camia, C. (2012). Santorum: English must be adopted by Puerto Rico. USA Today, 3. Retrieved from http://content.usatoday.com/communities/onpolitics/ post/2012/03/rick-santorum-puerto-rico-english-statehood-/1\#.Uusn6vldV2I

Carter, N. P., Hawkins, T. N., \& Natesan, P. (2008). The relationship between verve and the academic achievement of African American students in reading and mathematics in an urban middle school. Educational Foundations, 22(1-2), 29-46.

Cole, D. (1999). Race, policing, and the future of the criminal law. Human Rights, 26(3), $1-$ 3.

Council for Exceptional Children and the National Alliance of Black School Educators, (2002). Addressing over-representation of African American students in special education: The prereferral intervention process, an administrator's guide. Retrieved on January 11, 2003

from http://www.ideapractices.org/resources/topic.php?subcatID=76

Dewey, J. Philosophy of Education. http://www.wilderdom.com/experiential/JohnDeweyPhilosophyEducation.html. Accessed December 2017.

Flanagan, K. (2013). The reason every kid should talk back to their parents. UnTangled. Retrieved from http://drkellyflanagan.com/2013/11/06/the-reason-every-kidshould-talk-back-to-their-parents/

Flowers, D. (2000). Codeswitching and ebonics in urban adult basic education classrooms. Education and Urban Society, 32, 221-236.

Fordham, S. (1993). "Those loud black girls": (Black) women, silence, and gender "passing" in the academy. Anthropology \& Education Quarterly, 24(1), 3-32.

Freire, P \& Bergman-Ramos, M. (1996). Pedagogy of the Oppressed. London: Penguin Books

Guild, P. (2011). Diversity, learning style and culture. Johns Hopkins University. Retrieved from http://education.jhu.edu/PD/newhorizons/strategies/topics/ Learning\%20Styles/diversity.html

Higgins, P. \& Mackinem, M. (2008). Thinking about deviance: A realistic perspective. Lanham, MD: Rowan \& Littlefield Publishers, Inc.

Jabbra, N. (2001). Affirmative Action and the stigma of gender and ethnicity: California in the 1990s. Journal of Asian and African Studies, 36, 253-274

Jenkins, P. H. (1995). School delinquency and school commitment. Sociology of Education, 68(3), 221-239.

Kododo,W \& and Zanga, S. (2015). Implementation of the 2006 Education Amendment Act on Indigenous Languages in Zimbabwe: A Case of the Shangaan Medium in Cluster 2 Primary Schools in the Chiredzi District. International Journal of Learning, Teaching and Educational Research Vol. 11, No. 1, pp. 117-127.

Koonce, J. B. (2012). "Oh, those loud black girls!": A phenomenological study of black girls talking with an attitude. Journal of Language and Literacy Education, 8(2), 26-46.

Lindsay, B. (2003). Insights from Ralph Bunche: University-wide policies on internationalization to ameliorate diplomatic and socio-political realities. Paper 
presented at the annual conference of the Comparative and International Education Society, New Orleans, LA.

Linn, M. D. (1975). Black rhetoric and the teaching of composition. College Composition and Communication, 149-153.

Mayher, J. (1974). Yes, Virginia, there is a BEV [Black English Vernacular]. Paper presented at the Annual Conference on English Education.

McKenna, J. (2013). The disproportionate representation of African Americans in programs for students with emotional and behavioral disorders. Preventing School Failure, 57(4), 206-211.

Moore, M. (2003). Socially isolated: How parents and neighbourhood adults influence youth behavior in disadvantaged communities. Ethics \& Racial Studies, 26(6), 9881005.

Morris, E. (2007). "Ladies" or "loudies"? Youth \& Society, 38(4), 490-515.

Napa Wine Train Incident. http://www.cnn.com/videos/us/2015/08/25/napa-winetrain-nr.cnn Accessed November 30, 2017

Perez, T. E. (2010). https://www.justice.gov/archives/opa/ blog/civil-rights-andschool-discipline. Accessed December 1, 2017

Phelan, J. \& Rudman, L. (2010). Reactions to ethnic deviance: The role of backlash in racial stereotype maintenance. Journal of Personality \& Social Psychology. 99(2), 265281.

Prison statistics. (2007). Bureau of Justice Statistics. Retrieved January 28, 2014 from http://www.oip.usdoi.gov/bjs/prisons.htm

Robinson, D \& Lewis, C. W. (2017). Typologies for Effectiveness: Characteristics of Effective Teachers in Urban Learning Environments: JULTR, 2017, 124

Rocque, M. (2010). Office discipline and student behavior: Does race matter? American Journal of Education, 116(4), 557-581.

Simone, I-L. (2013). Gender, race, and justifications for group exclusion: Urban black students bussed to affluent suburban schools. Sociology of Education, 86(3), 218-233.

Skiba, R., Michael, R., Nardo, \& Peterson, R. (2002). The Color of Discipline: Sources of Racial and Gender Disproportionality in School Punishment. The Urban Review, Vol. 34, No. 4, December 2002.

Skiba, R., Poloni-Staudinger, L., Gallini, S., Simmons, A., Feggins-Azziz, R. (2006). Disparate access: The disproportionality of African American students with disabilities across educational environments. Exceptional Children, 72(4), 411-424.

The color of discipline: Sources of racial and gender disproportionality in school punishment. (2014). U.S. Department of Education. Retrieved from http://www2.ed.gov/policy/gen/ guid/school-discipline/index.html

Troutman, D. (2010). Attitude and its situatedness in linguistic politeness. Poznan Studies in Contemporary Linguistics, 46(1), 85-109.

Tyler, K. M., Uqdah, A. L., Dillihunt, M. L., Beatty-Hazelbaker, R., Conner, T., Gadson, N., Stevens, R. (2008). Cultural discontinuity: Toward a quantitative investigation of a major hypothesis in education. Educational Researcher, 37(5), 280-297.

Ulmer, J. (2000). Commitment, deviance, and social control. Sociological Quarterly, 41(3), 315-336.

$\begin{array}{lllll}\text { U. S. Bureau } & \text { of Justice } & \text { Statistics, } & 2007 .\end{array}$ https://www.bjs.gov/index.cfm?ty=pbdetail\&iid=764

U.S. Department of Education (2014). https://nationalblueribbonschools.ed. gov/awardwinners/ winning/...Maintaining, Collecting, and Reporting Racial and Ethnic Data to the U.S. . S Student turnover, or mobility rate, during the 2012-2013 year.

U. S. Department of Justice, (2010). https://www.justice.gov/archives/opa/blog/civilrights- and-school-discipline. 
Watkins, A. F. (2002). Learning styles of African American children: A developmental consideration. Journal of Black Psychology, 28(1), 3-17. Retrieved from http://ibp.sagepub.com/

Weber, L. (2010). Understanding race, class, gender, and sexuality: A conceptual framework (2nd ed.). New York: Oxford Press.

Zhang, D., Katsiyannis, A. Ju, S. \& Roberts, E. (2014). Minority representation in special education: 5-year trends. Journal of Child \& Family Studies, 23(1), 118-127. 